\title{
A Review on Kinetic Study of Thermal Degradation of Plastic
}

\author{
Jigisha Modi* \\ Shroff SR Rotary Institute of Chemical Technology, India \\ *Corresponding author: Jigisha Modi, Shroff SR Rotary Institute of Chemical Technology, India
}

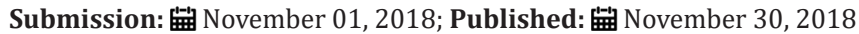

\begin{abstract}
Pyrolysis is thermal decomposition or degradation of material in the absence of oxygen which includes heating of plastic from ambient temperature to $900{ }^{\circ} \mathrm{C}$ in generally presence of nitrogen. Isothermal decomposition of plastic consists of decomposition of plastic from ambient temperature to required temperature at constant heating rate, whereas non-isothermal decomposition of plastic includes decomposition of plastic implied at different heating rates. Different types of waste plastics can be categorized as are Polyethylene (PE), Polypropylene (PP), Polyvinylchloride (PVC), Polystyrene (PS), Polyethylene terephthalate (PET), etc. This paper includes a mini review on kinetic study on thermal degradation of plastic.
\end{abstract}

Keywords: Plastic waste; Pyrolysis; Kinetic model

\section{Introduction}

Plastics are a generic group of synthetic or natural materials, composed of high-molecular chains whose sole or major element is carbon. Plastics are more convenient than other materials because of their resistance to degradation, light weight, some mechanical properties and low price. None of the commonly used plastics are biodegradable. As a result, they accumulate, rather than decompose, in landfills or the natural environment. The only way to permanently eliminate plastic waste is by destructive thermal treatment, such as combustion or pyrolysis. Plastic debris has been found in all major ocean basins, with an estimated 4 to 12 million metric tons of plastic waste generated on land entering the marine environment in 2010 alone. Without waste management infrastructure improvements, the cumulative quantity of plastic waste available to enter the ocean from land is predicted to increase by an order of magnitude by 2025 [1]. By the end of 2015, all plastic waste ever generated from primary plastics had reached 5800 metric tonne. Furthermore, contamination and the mixing of polymer types by various processing operations generate secondary plastics of limited or low technical and economic value. Plastics can be discarded or can be collected in a well-managed system, such as sanitary landfills, or left uncontained in open dumps or in the natural environment.

Global recycling and incineration rates have slowly increased to account for 18 and 24\%, respectively, of non-fibre plastic waste generated in 2014. Only some $15-20 \%$ of all waste plastics can be effectively recycled by conventional mechanical recycling technologies [2]. Beyond this level the plastics become increasingly commingled and contaminated with extraneous materials such as soil, dirt, aluminum foils, paper labels and food remain. Waste is typically categorized based on its point of generation in which major categories include municipal, commercial, industrial, agricultural and construction and demolition(C\&D). Considering these multiple categories, it is difficult to compare waste composition between countries. Plastic waste mainly consists of high-density polyethylene (HDPE), low-density polyethylene (LDPE), polypropylene (PP), polystyrene (PS), polyvinylchloride (PVC), polyethylene terephthalate (PET). Among the various categories of plastic waste the most common of them is plastic waste is polyethylene (PE) which makes about $40 \%$ of plastic waste [3]. Polyethylene terephthalate is commonly recycled.

There are different methods available for recycling of plastic waste, like mechanical recycling, chemical recycling. The most common method for the recycling of plastic waste is mechanical recycling. This process typically includes collection, sorting, washing and grinding of the material. Steps may occur in a different order, multiple times or not at all, depending on the origins and composition of the waste. Chemical recycling includes chemolysis, pyrolysis, fluid catalytic cracking, hydrogen technologies, KDV process, and gasification [4]. This study is mainly concentrated on study of pyrolysis of plastic waste. Pyrolysis is an interesting technology for plastic waste feeds that are difficult to depolymerize and that are currently not (mechanically) recycled but incinerated and/or dumped to landfill such as mixed PE/PP/PS, multilayer packaging, fibre-reinforced composites, polyurethane construction and demolishing waste. Pyrolysis process takes place at ambient temperature to high temperature $\left(900{ }^{\circ} \mathrm{C}, 1-2 \mathrm{~atm}\right)$ in absence of oxygen. The high temperatures allow breaking down the macrostructure of the polymer to form smaller molecules [5]. 
Park et al. [6] studied the pyrolysis characteristics of refuse plastic fuel (RPF) using lab-scale tube furnace and thermogravimetric analysis. In this, Product yields of liquid, solid, and gas were obtained from pyrolysis experiments on RPF using a tube furnace in a nitrogen atmosphere under three non-isothermal conditions (maximum temperature: $400{ }^{\circ} \mathrm{C}, 600{ }^{\circ} \mathrm{C}$ and $800{ }^{\circ} \mathrm{C}$ ). And, the effect of the temperature on the product yields of liquid, solid, and gas were discussed. The gas compositions and liquid compounds were analysed using gas chromatography (GC) and gas chromatography mass spectrum detector (GC-MSD), respectively. Using a Thermogravimetric analysis (TGA) reactor, thermal decomposition characteristics of PS, PVC, LDPE, and PP as well as RPF during pyrolysis were analyzed.

Kiran $\mathrm{N}$ et al. [7] studied recycling of plastic wastes (PE, PS) via pyrolysis using a Gray-King apparatus with different compositions. The chosen heating rate was low in order to achieve higher liquid yields. The results showed that waste PS yielded higher liquid, and waste PE yielded higher gaseous products. The dominant liquid product of PS waste was styrene whereas for waste PE, prophenyl benzene was the dominant pyrolysis product. Jin et al. [8] studied the kinetic analysis of pyrolysis of PE using dynamic method. The method was applied to predict the thermal degradation of highdensity polyethylene (HDPE), low-density poly-ethylene (LDPE) and linear low-density polyethylene (LLDPE) by a conventional non-isothermal thermogravimetric technique at several heating rates between 10 and $50{ }^{\circ} \mathrm{C} / \mathrm{min}$. Initial mass of sample taken was 22-25mg. The experiments were carried out in a nitrogen atmosphere with a low rate of $50 \mathrm{ml} / \mathrm{min}$ and a purge time of $20 \mathrm{~min}$.

\section{Conclusion}

Consumption of plastics has increased over the years and the concern with their waste generated too. Because of this many study have been done with the aim to recover or recycle the plastic waste. Only way to permanently eliminate plastic waste is by destructive thermal treatment, such as combustion or pyrolysis. A review regarding kinetics of plastic waste has been made which will be similar in various reactor levels..

\section{References}

1. Jambeck JR, Geyer R, Wilcox C, Siegler TR, Perryman M, et al. (2015) Marine pollution. Plastic waste inputs from land into the ocean. Science 347(6223): 768-771

2. Shojai MS, Bakhshandeh GR (2011) Recycling of PVC wastes. Polymer Degradation and Stability 96(4): 404-415.

3. Roland G, Jenna RJ, Kara LL (2017) Production, use, and fate of all plastics ever made. Science Advances 3 (7): e1700782.

4. Kim R, Laurens D, Kevin VG (2017) Mechanical and chemical recycling of solid plastic waste. Waste Management 69: 24-58.

5. Rofiqul I, Parveen M, Haniu H, Islam S (2010) Innovation in pyrolysis technology for management of scrap tire: a solution of energy and environment. International Journal of Environmental Science and Development 1(1): 89-96.

6. Jamal Y, Kim M, Park H (2016) Isothermal combustion kinetics of synthetic refuse plastic fuel (RPF) blends by thermogravimetric analysis. Applied thermal Engineering 104: 16-23.

7. Kiran N, Ekinci E, Snape CE (2000) Recyling of plastic wastes via pyrolysis. Resources Conservation and Recycling 29(4): 273-283.

8. Jin WP, Sea CO, Hae PL, Hee TK, Kyong OY (2000) Kinetic analysis of thermal decomposition of polymer using a dynamic model. Korean Journal of Chemical Engineering 17(5): 489-496.
Creative Commons Attribution 4.0 International License

For possible submissions Click Here
Submit Article

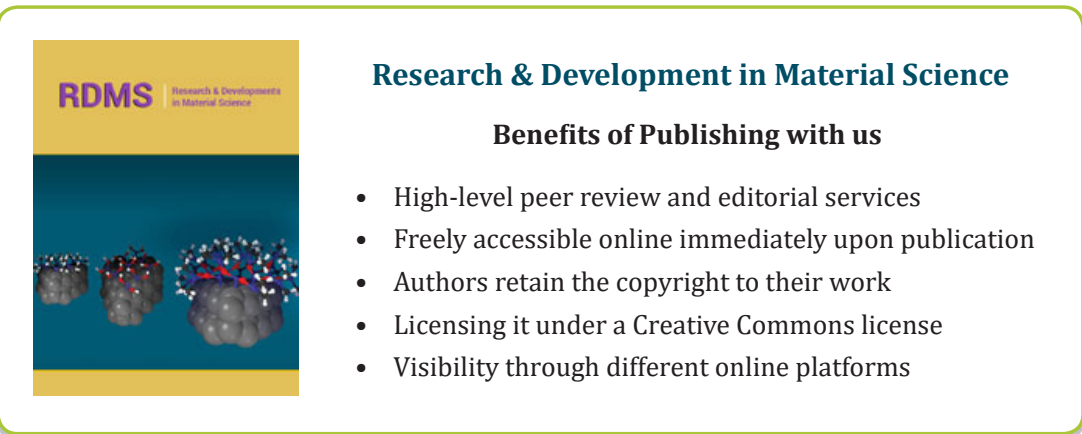

